\title{
Production and Characterization of Biodiesel from Cotton Oil as an Alternative Energy in Substitution of Soybean Oil
}

\author{
Jean Agustin Velásquez-Piñas ${ }^{1, *}$, Pedro Jessid Pacheco-Torres ${ }^{2}$, Orly Denisse Calle ${ }^{3}$, Leidy Milena \\ Mora-Higuera $^{4}$, John-William Grimaldo-Guerrero $^{5}$ and Martha Patricia de-la-Ossa-Ruiz ${ }^{6}$ \\ ${ }^{1}$ Laboratory of Photochemistry and Materials Science - LABFOT-CM. Institute of Chemistry. Universidade Federal de Uberlândia - \\ UFU Santa Monica Campus. Santa Monica, Uberlândia, MG, Brazil. \\ ${ }^{2}$ Reformed community of research and development in engineering - CRIDI, Faculty of Engineering. Corporación Universitaria \\ Reformada - CUR. Barranquilla, AT, Colombia \\ ${ }^{3}$ Incubation Centre of Social Solidarity Enterprises-CIEPS, Universidade Federal de Uberlândia, Campus Santa Mônica, Uberlândia- \\ $M G$, Brazil \\ ${ }^{4}$ Investigation in Rural, logistic and Economic Development, Freelance Consultant, Bogotá, Colombia \\ ${ }^{5}$ Department of Energy, Energy Optimization Research Group GIOPEN, Universidad de la Costa, Barranquilla, Colombia. \\ ${ }^{6}$ Green Energy Foundation, FUNGRENY, Barranquilla, Colombia.
}

Received 3 December 2018; Accepted 31 December 2018

\begin{abstract}
Biodiesel production has currently used virgin raw materials that have a direct use for mainly food uses, as in the case of vegetable oils, mainly soybean, and may in some cases affect food safety. Raw materials such as cotton oils that are obtained from seeds, which are the residual products of productive chains, can help food security, energy and the exploration of new sources of energy of less environmental impact. The present work investigated the chemical and physical characteristics of biodiesel produced from cotton oil in comparison to soybean oil (BOA). The results show that the acidity and viscosity of the BOA are within the permissible values of ANP 03/2014, and the viscosity of the BOA product of the transesterification of soybean oil has values of $4.41 \pm 0.20 \mathrm{~mm}^{2} \mathrm{~s}^{-1}$. Finally, it can be concluded that cotton oil may be an alternative to replace soybean oil; however, the availability of raw material may play an important role.
\end{abstract}

Keywords: Biodiesel, cotton oil, soybean oil, transesterification.

\section{Introduction}

The indiscriminate use of fossil fuels and their resulting environmental problems has stimulated the search for and development of new, renewable sources for energy production $[1,2]$. Biodiesel can be considered as a renewable source, even if its combustion can cause the emission of carbon dioxide ( $\mathrm{CO} 2)$, this can be converted again into biomass through photosynthesis, this means that the $\mathrm{CO} 2$ produced should not in principle contribute to the imbalance of the chemical composition of the atmosphere that could aggravate global warming [3, 4]. However, this may depend on the inherent characteristics of the inputs used to produce biodiesel, and may not have a completely neutral balance sheet when some of the inputs are not from renewable sources [5].

Biodiesel refers to a form of vegetable oil or animal fatbased diesel fuel and as a very promising alternative to replace the diesel oil $[6,7]$. One of the renewable fuels widely investigated in the last decade is the alkyl ester derived from long chain fatty acids, better known as biodiesel $[1,8,9]$, which can be produced from vegetable oils and animal fats $[10,11]$. Vegetable oils and animal fats can not be used directly in diesel engines because of their

*E-mail address: jwgrimal@gmail.com

ISSN: 1791-2377 @ 2018 Eastern Macedonia and Thrace Institute of Technology. All rights reserved.

doi:10.25103/jestr.116.23 high viscosity, high density, high glow point and low calorific power. The use of biodiesel as a substitute for diesel oil is mainly due to their similar physical and chemical characteristics $[9,12,13]$. However, the use of raw materials, alcohols, and catalysts can directly shave the properties of biodiesel [14, 15].

The most used raw materials for biodiesel production in the US and Europe are soybean (Glycine max) and rapeseed (Brassica napus), respectively. In Brazil the main raw materials used for biodiesel production are and soybean oil $(70 \%)$ and bovine tallow (16\%) [16]. However, in Brazil, cotton oil is also having an important share in the oil mix to produce biodiesel [17], with the amount of oil of cotton used was increased from $1,904 \mathrm{~m} 3$ of the year 2007 to $78,840 \mathrm{~m} 3$ to the year 2015 being the third most used oleaginous input (2\%) [17].

The properties of biofuels, specifically biodiesel (B100), are governed by technical specifications that depend on the geographical scope in the place where they are, and for the European Union are based on the EN-14214 standards, for the US with the ASTM D-6751 [14], and for the Brazilian territory the ANP standard 03/2014 [18]. Table 1 shows the permissible limits of the European, North American and Brazilian specifications for biodiesel B100, and these have some variations that depend mainly on the inputs used for their production. 
Table 1.Biodiesel technical specifications for B100: Brazilian (ANP), European (EN) and North American standards (ASTM)

\begin{tabular}{|c|c|c|c|c|}
\hline Specification/Properties & Units & ANP 03/2014 & EN-14214 & ASTM-D6751 \\
\hline Specific mass at $20^{\circ} \mathrm{C}$ & $\mathrm{g} / \mathrm{cm}^{3}$ & $0,85-0,90$ & $0,86-0,90$ & - \\
\hline Kinematic viscosity at $40^{\circ} \mathrm{C}$ & $\mathrm{mm}^{2} / \mathrm{s}$ & $3,0-6,0$ & $3,50-5,00$ & $1,9-6,0$ \\
\hline Flash point & ${ }^{\circ} \mathrm{C}$ & $100 \mathrm{~min}$ & $120 \mathrm{~min}$ & $130 \mathrm{~min}$ \\
\hline Cetane number & - & - & $51 \mathrm{~min}$ & $47 \mathrm{~min}$ \\
\hline Sulphur & $\mathrm{mg} / \mathrm{kg}$ & $5,0 \max$ & $10,0 \max$ & $15,0 \max$ \\
\hline Phosphorus & $\mathrm{mg} / \mathrm{kg}$ & $10,0 \max$ & $10,0 \max$ & $10,0 \max$ \\
\hline Water content & $\mathrm{mg} / \mathrm{kg}$ & $200 \max$ & $500 \max$ & $500 \max$ \\
\hline Acid value & $\mathrm{mg} \mathrm{KOH} / \mathrm{g}$ & $0,50 \max$ & $0,50 \max$ & $0,80 \max$ \\
\hline Free glycerol & $\%$ weight & $0,02 \max$ & $0,02 \max$ & $0,02 \max$ \\
\hline Total glycerol & $\%$ weight & $0,25 \max$ & $0,25 \max$ & $0,24 \max$ \\
\hline Sulphated ashes & $\%$ weight & $0,020 \max$ & $0,020 \max$ & 0,020 max \\
\hline Methanol & $\%$ weight & $0,20 \max$ & $0,20 \max$ & - \\
\hline Monoacilglycerol & $\%$ weight & $0,70 \max$ & $0,80 \max$ & - \\
\hline Diacilglycerol & $\%$ weight & $0,20 \max$ & $0,20 \max$ & - \\
\hline Triacilglycerol & $\%$ weight & $0,20 \max$ & $0,20 \max$ & - \\
\hline Esters content & $\%$ weight & $96,5 \mathrm{~min}$ & $96,5 \mathrm{~min}$ & - \\
\hline Iodine value & - & - & $120 \max$ & - \\
\hline Oxidation stability at $110^{\circ} \mathrm{C}$ & $\mathrm{h}$ & $6 \mathrm{~min}$ & $6 \mathrm{~min}$ & - \\
\hline $\begin{array}{l}\text { Corrosiveness by the copper } \\
\text { (NBR } 14359), 3 \mathrm{~h} \text { a } 50^{\circ} \mathrm{C}\end{array}$ & - & No. 1 & No. 1 & No. 3 \\
\hline
\end{tabular}

\section{Methodology}

\section{A. Biodiesel synthesis}

The biodiesel produced was through the methyl route by means of basic transesterification of refined soybean oil (SO) and cotton oil (CO). The catalyst used for the reaction was $\mathrm{KOH}$. The reaction conditions were performed taking into account the methodology described by [21]. The molar ratio of methanol and oil was $6: 1$, excess methanol would help complete the reaction by consuming all long chain fatty acids. The amount of catalyst to be used was $0.6 \%$ with respect to the mass of the oil. The reaction temperature was $55^{\circ} \mathrm{C}$ kept constant for 60 minutes, the oil had to be preheated to $50^{\circ} \mathrm{C}$ before adding the catalyst and methanol (monoxide) mixture. The stirring has to be kept constant and at low speed allowing the mixture of the oil with the methoxide, a stirring speed near $300 \mathrm{rpm}$ is recommended.

Figure 1 shows the details of the experimental apparatus installed to perform biodiesel synthesis, the system must be assembled taking into account that it is completely closed so that the methanol can react with the oil. The condensation system will allow recovery of methanol.

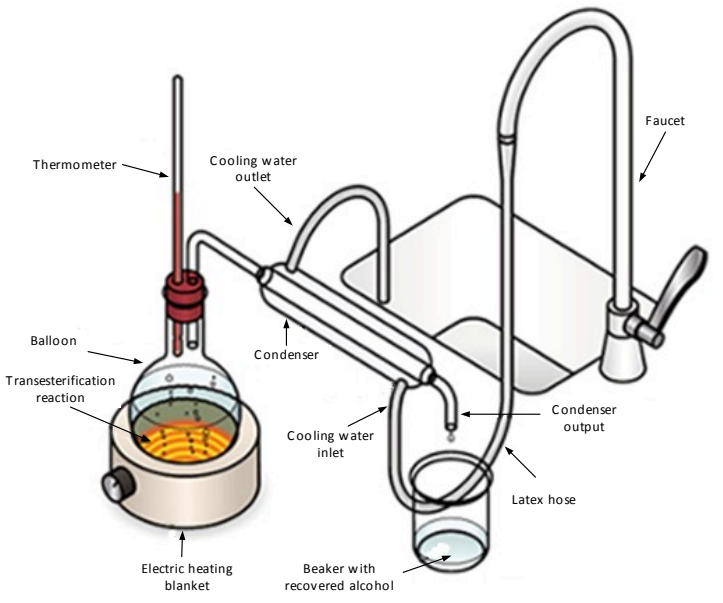

Fig. 1. Scheme of the system for the synthesis of biodiesel.
The obtained biodiesel (raw biodiesel) of both soybean (BSO) and cotton (BCO), after the reaction was separated by decanting in a funnel for phase separation for 12 hours, after which the biodiesel yield was quantified according to equation 1 described by $[21,22,23]$. Subsequently the raw biodiesel after decantation was washed with distilled water at $50^{\circ} \mathrm{C}$ for 5 sequential times, during this process the $\mathrm{pH}$ of the wash water decreased from 11 to 6.5 , close to neutral value.

Yield $_{\text {biodiesel }}(\%)=\frac{\text { weight of raw biodiesel }}{\text { weight of oil used }} \times 100$

\section{B. Characterization analysis a. Ester content}

The ester content was determined by the analysis of gas chromatography, following the standard EN 14103 (2001). A gaseous chromatograph Shimadzu-GC with flame ionization detector, RTX-Wax capillary column (Restek, 30 $\mathrm{m}, 0.32 \mathrm{~mm}$ id, $0.25 \mu \mathrm{m} \mathrm{df})$, split injection (1:50) and injector temperature at $250{ }^{\circ} \mathrm{C}$ was used. The volume injected was $1 \mu \mathrm{L}$, column temperature: $210^{\circ} \mathrm{C}$ and the entrainment gas was helium, with a flow rate of $30 \mathrm{~mL} / \mathrm{min}$. Calculation of the ester content is performed using equation 2.

Esteres $(\%)=\left(\frac{\sum A-A P I}{A P I} \times \frac{C P I}{C_{\text {sample }}}\right) \times 100$

At where; $\sum A$ is the sum of the areas corresponding to the peaks of the esters (C14:0 to C24:0); API is the area of the internal standard (C17:0 - methyl heptadecanoate); CPI is the concentration of the internal standard in the sample injected $(\mathrm{mg} / \mathrm{L})$ and $C_{\text {sample }}$ is the concentration of the sample injected $(\mathrm{mg} / \mathrm{L})$.

\section{b. Acidity Index (AI) and Free Fatty Acids (FFA)}

The analyzes of acidity index and the percentage of free fatty acids were carried out on the samples of vegetable oil, as well as on the biodiesel obtained. The procedure for the analysis is to know the amount of $\mathrm{KOH}$ in concentration of $0.1 \mathrm{M}$ required for the neutralization of one gram of sample 
which is previously dissolved in $25 \mathrm{ml}$ of a neutral solvent mixture consisting of diethyl ether and absolute ethanol in 1:1 ratio to which 3 phenolphthalein drops are added as indicator and titrated until the coloration of the solution turns pink. The acidity can be calculated according to equation 3 . The percentage of free fatty acids is calculated using equation 4, which expresses the percentage in terms of oleic acid.

$$
\begin{aligned}
& A I(m g K O H / g)=\frac{5,61 \times M \times V}{W} \times 100 \\
& F F A(\%)=\frac{28,2 \times M \times V}{W} \times 100
\end{aligned}
$$

At where; $\mathrm{M}$ is the molarity of $\mathrm{KOH}$; $\mathrm{V}$ is the volume of $\mathrm{KOH}$ consumed in titration in $\mathrm{mL}$; $\mathrm{W}$ is the mass in grams of the sample to holder; 5.61 is the molecular mass of potassium hydroxide; and 28.2 is a constant (mass of oleic acid neutralized by $1 \mathrm{mg}$ of $\mathrm{KOH}$ ).

\section{c. Dynamic and kinematic viscosity}

Viscosity is the resistance that the fluid presents to the flow. The rheological behavior of the samples, both oil and biodiesel, were evaluated by means of the absolute (dynamic) viscosity using the Brookfield viscometer model DVIII ultra. Absolute or dynamic viscosity measures the force required to move a unit of area to a unit distance and the result is given in $\mathrm{cP}$ or $\mathrm{mPa}$.se and can be calculated by equation 5. The kinematic viscosity determines the relationship between the dynamic viscosity and a density of the fluid through equation 6 , in which case it can use standard values of the different fluids of table 2 .

$\tau_{y x}=\mu \frac{d v}{d y}$

At where; $\tau_{y x}$ is the shear stress $(\mathrm{mPa}) ; \mu$ is the dynamic viscosity (mPa.s); and $d v / d y$ is the shear rate (s-1)

$v=\frac{\mu}{\rho}$

At where; $v$ is the kinematic viscosity $(\mathrm{mm} 2 / \mathrm{s}) ; \mu$ is the dynamic viscosity (mPa.s); and $\rho$ is the fluid density ( $\mathrm{kg} /$ $\mathrm{m} 3)$.

Table 2. Densities in $\mathrm{g} / \mathrm{ml}$ oil and biodiesel of cotton and soybean.

\begin{tabular}{c|c|c|c}
\hline Fluid Density & Sample & Value & Reference \\
\hline Cotton oil density $\left(25^{\circ} \mathrm{C}\right)$ & $\mathrm{CO}$ & 0,9170 & {$[17]$} \\
Soybean oil density $\left(25^{\circ} \mathrm{C}\right)$ & SO & 0,9175 & {$[17]$} \\
Cotton biodiesel density $\left(15^{\circ} \mathrm{C}\right)$ & BCO & 0,8828 & {$[10]$} \\
Soybean biodiesel density $\left(15^{\circ} \mathrm{C}\right)$ & BSO & 0,8840 & {$[10]$} \\
\hline Soure:
\end{tabular}

\section{Results and discussion}

The yield obtained in the transesterification reaction was higher than $100 \%$, yielding $103 \%$ for biodiesel of soybean oil and $108 \%$ for biodiesel of cotton oil. According to [20], yields above $98 \%$ can be reached for transesterification reactions with homogeneous alkaline catalysts, and, for supercritical processes where the catalyst is not used [27, 28], yields between $85-90 \%$ can be obtained [6]. According to [21], it is possible to reach yields in excess of $100 \%$ by mass, but the molar yields can not exceed $100 \%$, this may depend on the type of alcohol used, higher alcohols may lead to higher yields $[29,30]$; the higher or fusel alcohols have more than 2 carbons, thus have higher molecular weight and higher boiling point [29]. However, the chromatography values used to determine the percentage of esters present in biodiesel suggest that there may still be monoglycerides, diglycerides and triglycerides, as well as present glycerol may have increased yield, considering that the percentage of methyl esters for biodiesel from cotton and soy were $68.87 \%$ and $69.06 \%$ respectively.

The oils used in both cotton and soybean have the best characteristics for the production of biodiesel, which have a low acidity because they are refined oils, with an acid value of $0.04 \pm 0.001$ for cotton oil and $0,13 \pm 0.02$ for soybean oil. In addition, vegetable oils by their inherent characteristics have a high kinematic viscosity, as shown in table 3 , which is decreased by the transesterification process.

Table 3. Physicochemical properties of cotton oil (CO) and soybean (SO).

\begin{tabular}{cccc}
\hline Property & Unit & CO & SO \\
\hline Acid value & $\mathrm{mg} \mathrm{KOH} / \mathrm{g}$ & $0,04 \pm 0,001$ & $0,13 \pm 0,02$ \\
Free Fat Acids & $\% \mathrm{AGL}$ & $0,19 \pm 0,01$ & $0,66 \pm 0,08$ \\
Dynamic viscosity & $\mathrm{mPa} . \mathrm{s}$ & $36,45 \pm 1,13$ & $35,83 \pm 1,32$ \\
Kinematic viscosity & $\mathrm{mm}^{2} . \mathrm{s}^{-1}$ & $39,75 \pm 1,28$ & $39,05 \pm 1,50$ \\
\hline
\end{tabular}

Table 4 shows the characteristics of the biodiesel obtained from the basic transesterification of soybean and cotton oils. Characteristics such as acidity presented values of $0.02 \pm 0.0001$ for cotton biodiesel and $0.03 \pm 0.0003$ for soybean biodiesel. The viscosity of the obtained biodiesel corresponds to the viscosity of the Newtonian fluids, which can be confirmed by Figure 2, which shows the shear rate (s -1) versus shear stress $(\mathrm{mPa})$ and the shear rate $(\mathrm{s}-1)$ versus Dynamic viscosity (mPa.s), with Newtonian fluids having a linearity in the graphs shown, different from non-Newtonian fluids. The kinematic viscosity values for biodiesel obtained from cotton oil were $4.46 \pm 0.20$ and for soybean biodiesel was $4.41 \pm 0.20$.

The obtained values of acidity and viscosity are within the permissible limits of the Brazilian standard that regulates the quality of biodiesel produced. However the ester content of the biodiesel produced does not exceed the minimum value of $96.5 \%$ allowed, mainly due to the fact that the reaction may not have been completed.

Table 4. Chemical physical properties of cotton biodiesel

\begin{tabular}{|c|c|c|c|c|}
\hline Property & Unit & BCO & BSO & $\begin{array}{c}\text { ANP } \\
03 / 2014\end{array}$ \\
\hline Acid value & $\begin{array}{c}\mathrm{mg} \\
\mathrm{KOH} / \mathrm{g}\end{array}$ & $\begin{array}{l}0,02 \pm \\
0,0001\end{array}$ & $\begin{array}{l}0,03 \pm \\
0,0003\end{array}$ & $0,50 \max$ \\
\hline Free Fat Acids & $\% \mathrm{AGL}$ & $\begin{array}{l}0,10 \pm \\
0,0005\end{array}$ & $\begin{array}{c}0,15 \pm \\
0,001\end{array}$ & - \\
\hline $\begin{array}{l}\text { Dynamic } \\
\text { viscosity }\end{array}$ & mPa.s & $\begin{array}{c}3,89 \pm \\
0,18\end{array}$ & $\begin{array}{c}3,94 \pm \\
0,18\end{array}$ & - \\
\hline $\begin{array}{c}\text { Kinematic } \\
\text { viscosity }\end{array}$ & $\mathrm{mm}_{1}^{2} \cdot \mathrm{s}^{-}$ & $\begin{array}{c}4,41 \pm \\
0,20\end{array}$ & $\begin{array}{c}4,46 \pm \\
0,20\end{array}$ & $3,0-6,0$ \\
\hline Ester content & $\%$ & 68,87 & 69,06 & $96,5 \mathrm{~min}$ \\
\hline
\end{tabular}
(BCO) and soybean biodiesel (BSO). 


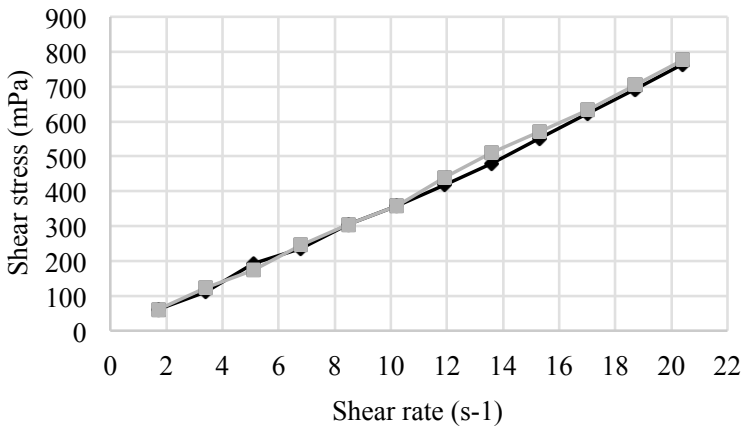

$\longrightarrow$ Soy oil $\longrightarrow$ Cotton Oil

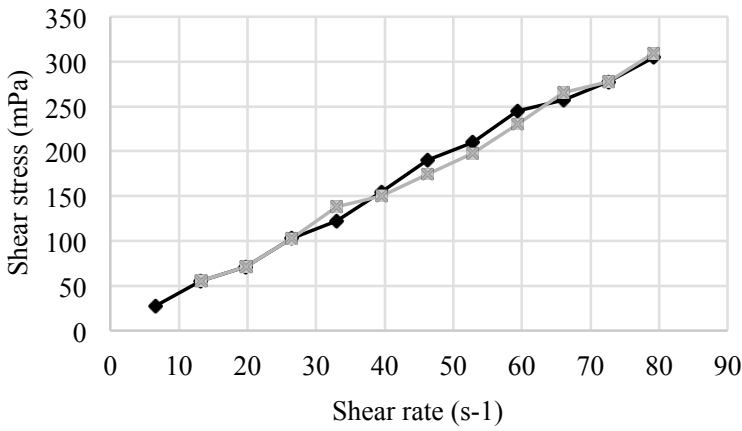

$\longrightarrow$ Soybean Biodiesel $\because$ Cotton Biodiesel

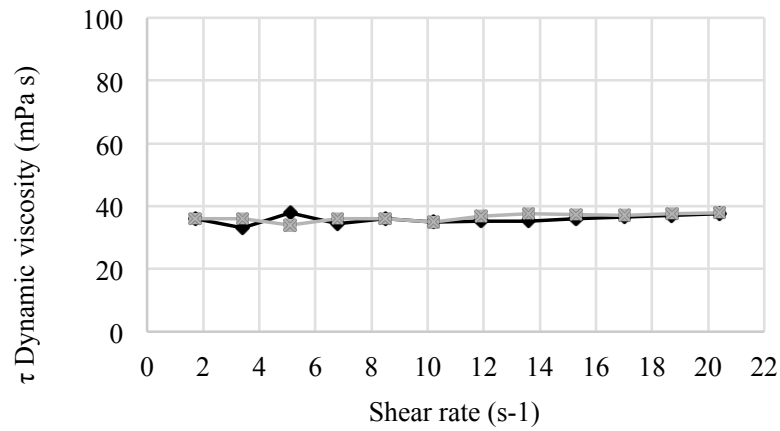

$\longrightarrow$ Soy oil $\longrightarrow$ Cotton Oil

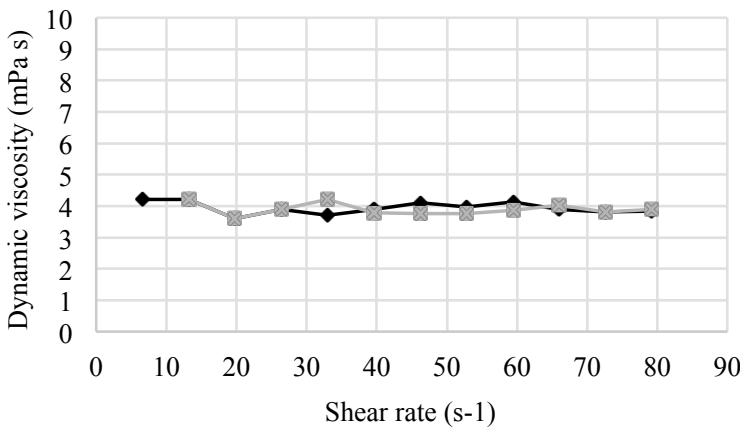

$\longrightarrow$ Soybean Biodiesel $\longrightarrow$ Cotton Biodiesel

Fig. 2. Characteristic graph of Newtonian fluids made for soybean and cotton oils and soybean and cotton biodiesel.

\section{Conclusions}

Soybean oil biodiesel has a higher yield than cotton oil biodiesel due mainly to the lower acidity that soybean oil has, considering that the raw materials used were refined oils of both cotton and soya.

Transesterification of vegetable oils by the methyl route reduces oil viscosity to values similar to petroleum diesel so that biodiesel can be used instead of fossil fuels, having kinematic viscosity values for the cotton oil biodiesel of 4.46 \pm 0.20 and for soybean biodiesel of $4.41 \pm 0.20$.

The oil of cotton has similar characteristics than the oil of soybean, being able to be used for the production of biodiesel in industrial scale; however, production on a scale that allows for profitability may depend on the quantity of raw material available, for which an assessment is still indispensable to know some characteristics in this sense.

\section{Acknowledgements}

The authors are grateful to the Coordination of Improvement of Higher Education (CAPES), the National Council for Scientific and Technological Development (CNPq), the Research Support Foundation of the State of Minas Gerais (FAPEMIG), the Laboratory of Photochemistry and Materials Science LABFOT-CM) and the Federal University of Uberlândia (UFU) for their collaboration in the development of this work.

This is an Open Access article distributed under the terms of the Creative Commons Attribution License

\section{References}

[1] J. Lafont, A. Espitia and J. Sodré, "Potential vegetable sources for biodiesel production: Cashew, coconut and cotton," Materials for Renewable and Sustainable Energy, vol. 4, no. 1, pp. 1-7, 2015.

[2] N. Kokkinos, A. Lazaridou, N. Stamatis, S. Orfanidis, A. C. Mitropoulos, A. Christoforidis and N. Nikolaou, "Biodiesel Production from Selected Microalgae Strains and Determination of its Properties and Combustion Specific Characteristics," Journal of Engineering Science \& Technology Review, vol. 8, no. 4, pp. 1-6, 2015.

[3] D. Huang, H. Zhou and L. Lin, "Biodiesel: An alternative to conventional fuel," Energy Procedia, vol. 16, no. PART C, p. 1874 $1885,2011$.

[4] A. Sagastume Gutiérrez, J. Cabello Eras, D. Huisingh, C. Vandecasteele and L. Hens, "The current potential of low-carbon economy and biomass-based electricity in Cuba. The case of sugarcane, energy cane and marabu (Dichrostachys cinerea) as biomass sources," Journal of Cleaner Production, vol. 172, no. 20, pp. 2108-2122, 2018.

[5] C. Alejos Altamirano, L. Yokoyama, J. De Medeiros and O. De Queiroz Fernandes Araújo, "Ethylic or methylic route to soybean biodiesel? Tracking environmental answers through life cycle assessment," Applied Energy, vol. 184, pp. 1246-1263, 2016.

[6] R. Fan, J. Zhao, Y. Du, W. Zhao, W. Guo, J. Yang and X. Chen, "Biodiesel production from Fructus Schisandrae seed oil," Indian Journal of Biotecnology, vol. 16, no. 1, pp. 114-118, 2017.

[7] S. Prabhakar and K. Annamalai, "Biodiesels: an alternative renewable energy for next century," Journal of scientific and industrial research, vol. 70, no. 10, pp. 875-878, 2011. 
[8] A. Samniang, C. Tipachan and S. Kajorncheappun-ngam, "Comparison of biodiesel production from crude Jatropha oil and Krating oil by supercritical methanol transesterification," Renewable Energy, vol. 68, p. 351-355, 2014.

[9] Y. Jiang and Y. Zhang, "Supply Chain Optimization of Biodiesel Produced from Waste Cooking Oil," Transportation Research Procedia, vol. 12, p. 938-949, 2016.

[10] M. Ali, M. Mashud, M. Rubel and R. Ahmad, "Biodiesel from Neem Oil as an Alternative Fuel for Diesel Engine," Procedia Engineering, vol. 56, pp. 625-630, 2013.

[11] P. Saxena, S. Jawale and M. Joshipura, "A review on prediction of properties of biodiesel and blends of biodiesel," Procedia Engineering, vol. 51, pp. 395-402, 2013.

[12] N. Kolesárová, M. Hutan, I. Bodík and V. Špalková, "Utilization of biodiesel by-products for biogas production," Journal of Biomedicine and Biotechnology, vol. 2011, 2011.

[13] H. Bashiri and N. Pourbeiram, "Biodiesel production through transesterification of soybean oil: A kinetic Monte Carlo study," Journal of Molecular Liquids, vol. 223, p. 10-15, 2016.

[14] E. Alptekin and M. Canakci, "Determination of the density and the viscosities of biodiesel-diesel fuel blends," Renewable Energy, vol. 33, no. 12, p. 2623-2630, 2008.

[15] K. A. Sorate and P. V. Bhale, "Impact of biodiesel on fuel system materials durability," Journal of scientific and industrial research, vol. 72, no. 1, pp. 48-57, 2013.

[16] M. Canakci, "Combustion characteristics of a turbocharged DI compression ignition engine fueled with petroleum diesel fuels and biodiesel," Bioresource Technology, vol. 98, no. 6, pp. 1167-1175, 2007.

[17] EPE, "Balanço Energético Nacional 2016: Ano Base 2015," Empresa de Pesquisa Energética, Rio de Janeiro, Brasil, 2016.

[18] ANP - Agência Nacional do Petróleo Gás Natural e Biocombustíveis, "Resolução No45/2014," Diário Oficial da União vol. 1, n.1, 2014

[19] V. Gurau and S. Sandhu, "Optimization and Characterization of Biodiesel Production from India Originated Bitter Apricot Kernel
Oil," Journal of scientific and industrial research, vol. 77, no. 06 , pp. $345-348,2018$.

[20] A. Deep, S. Sandhu and S. Chander, "Optimization of Reaction Parameters of Transesterification for Castor Oil," Journal of Scientific \& Industrial Research, vol. 76, no. 02, pp. 115-118, 2017.

[21] D. Onukwuli, L. Emembolu, C. Ude, S. Aliozo and M. Menkiti, "Optimization of biodiesel production from refined cotton seed oil and its characterization," Egyptian Journal of Petroleum, vol. 26, no. 01, pp. 103-110, 2016.

[22] D. Leung and Y. Guo, "Transesterification of neat and used frying oil: Optimization for biodiesel production," Fuel Processing Technology, vol. 87, no. 10, pp. 883-890, 2006.

[23] M. Alves, S. Nascimento, I. Pereira, M. Martins, V. Cardoso and M. Reis, "Biodiesel purification using micro and ultrafiltration membranes," Renewable Energy, vol. 58, pp. 15-20, 2013.

[24] F. Gunstone, Vegetable Oils in Food Technology: Composition, Properties and Uses, 2 ed., Oxford, UK: Wiley-Blackwell, 2011.

[25] I. Lôbo, S. Ferreira and R. Da Cruz, "Biodiesel: parâmetros de qualidade e métodos analíticos," Química Nova, vol. 32, no. 6, p. 1596-1608, 2009.

[26] S. Marda, Thesis of Master: Production of biodiesel from tall oil, New York: State University of New York College of Environmental Science and Forestry, 2006.

[27] G. Madras, C. Kolluru and R. Kumar, "Synthesis of biodiesel in supercritical fluids," Fuel, vol. 83, no. 14-15, pp. 2029-2033, 2004.

[28] J. Maçaira, A. Santana, F. Recasens and M. A. Larrayoz, "Biodiesel production using supercritical methanol/carbon dioxide mixtures in a continuous reactor," Fuel, vol. 90, no. 6, pp. 22802288, 2011.

[29] P. Patidar and S. M. Mahajani, "Esterification of fusel oil using reactive distillation - Part I: Reaction kinetics," Chemical Engineering Journal, Vols. 207-208, pp. 377-387, 2012.

[30] B. Zhang, Z. Zhong, J. Zhang and R. Ruan, "Catalytic fast copyrolysis of biomass and fusel alcohol to enhance aromatic hydrocarbon production over ZSM-5 catalyst in a fluidized bed reactor," Journal of Analytical and Applied Pyrolysis, vol. 133, no. , pp. 147-153, 2018. 